\title{
Relationship Between Assessment for Learning and English Learning Motivation of University Students in Blended Learning Environment
}

\author{
Wang $\mathrm{Lu}^{1,2^{*}} \quad$ Siti Maziha Mustapha ${ }^{2}$ \\ 1.College of Foreign Studies, Hubei Normal University, 11 Cihu Road, Huangshi, Hubei, China \\ 2.Faculty of Business, Information and Human Sciences, Infrastructure University Kuala Lumpur (IUKL), \\ 43000 Kajang, Selangor Darul Ehsan, Malaysia
}

The study was sponsored by Hubei Provincial Department of Education's Important Humanity and Social Sciences Research Project (Project ID: 16D068); Hubei Provincial Department of Education's Research Project on Teaching Reform in Colleges and Universities (Project ID: 2016490); Hubei Provincial Education Science Twelfth Five-year Plan Project (Project ID: 2014B113); Educational Ministry of Hubei Province (Project ID: 19Q307); College of foreign studies, Hubei Normal University (ID: 1705).

Abstract

Recently, assessment for learning (AFL) has gained increasing popularity by researchers worldwide. It is generally accepted that AFL enables students to optimize their learning process and improve their learning proficiency through various informal assessment. This study aims at investigating the relationship between AFL and English learning motivation at university level as well as students' perceptions of this kind of assessment in a blended learning course. Blended learning combines the advantages of traditional face-to-face classroom teaching with online learning in order to provide a better learning environment. Both quantitative and qualitative method were used in the study. The quantitative data comes from two questionnaires: Assessment for Learning Questionnaire for Students which consist of Monitoring and Scaffolding part was used to investigate students' perceptions of assessment for learning and the Motivation Subscale of Motivated Strategies for Learning Questionnaire was selected as the instrument to measure students' motivation, which was furthered divided into value component, expectancy component and affective component. 115 university students from Hubei Province of China completed the two questionnaires. The data collected were analyzed using SPSS 22.0. Qualitative data were collected from semi-structured interviews with the selected 6 students. The results of correlation analysis show that intrinsic goal orientation and task value of value component is positively correlated with AFL. Expectancy component is positively correlated with AFL. There is no significant correlation between extrinsic goal orientation and AFL. AFL is not significantly associated with test anxiety. Both monitoring and scaffolding factors contribute to the increase of students' motivation. Results of the interviews indicate that students with high language proficiency are more willing to accept AFL. It is suggested that AFL should be advocated and applied in teaching language course in China. Future studies are needed to investigate the influence of AFL on students' learning outcome in an all-around way.

Keywords: Assessment for learning; English learning motivation; University students; Blended Learning DOI: $10.7176 / \mathrm{JEP} / 11-5-09$

Publication date: February $29^{\text {th }} 2020$

\section{Background of Study}

Assessment is an indispensable part in teaching practice. The past 30 years have witnessed great changes of assessment system in China, which has undergone four stages, from the summative testing to formative assessment, from assessment of learning to assessment for learning (Wang Tongshun, Zhu Xiaotong \& Xu Yingying., 2018).

The traditional way of assessment occurred after the teaching activities, which highlighted the testing of students' learning results. Students' final marks or grades became the main source of assessment without monitoring or feedback of the whole learning process (Jin Yan, 2010). Due to the drawbacks of traditional assessment, formative assessment was valued by scholars for its emphasis on the process of learning and teaching (Cowie, B., \& Bell, B., 1999). However, formative assessment fails to include all the assessment measures to improve students' learning, which ushers in the emergence of AFL. AFL entails a wider range of assessment than formative assessment. Being goal-oriented and process-oriented, AFL utilizes a variety of assessment measures to track and monitor the learning process and provides timely feedback. It happens through the whole teaching practice so as to improve the quality of teaching and learning (Wang Tongshun et al., 2018). AFL consists of two parts: monitoring and scaffolding. Monitoring examines students' learning situation and tracking their progress by reflective feedback from practice and self-monitoring behavior. Scaffolding helps learners recognize their own deficiencies as well as ways to improve themselves based on clear goals and standards, effective questioning in class and suggestions from teachers (Stiggins, R.,2005; Heitink, M. C., Van 
der Kleij, F. M., Veldkamp, B. P., Schildkamp, K., \& Kippers, W. B., 2016). Sadler, D. R. (2010) pointed out metaphorically that monitoring answers the question "where are you now" and "where are you going to do" by providing the feedback of learning situation and current progress to learners while scaffolding offers the answer to the question "how to get there" by giving specific instructions and suggestions to further enhance learning efficiency.

\section{Problem Statement}

Assessment for learning (AFL) entails all the evaluation measures to optimize students' learning process and improve their learning outcome (Wiggins, G. P., 1993). With the development of AFL theory and its success in educational practice, it has received attention by scholars world wide and become a hot issue in educational research (Li Mang, Cai Yujun \& Chen Ping., 2016). Despite its popularity, there is a lack of studies focusing on AFL in China. The number of empirical studies concerned with AFL in English language class is rather limited.

Blended learning is defined as an instruction method which combines the advantages of traditional face-toface classroom teaching with online learning in order to provide a better learning environment (Dang, Y., Zhang, Y., Ravindran, S., \& Osmonbekov, T., 2016). In China, in order to keep pace with the development of technology, blended learning courses enjoy great popularity. It is considered that blended learning that emerged with the advancement of technology will become increasingly important in higher education (Akgündüz, D., \& Akınoğlu, O., 2017). However, up to date, there is lack of research concerning AFL in blended learning course.

According to Clayton, K., Blumberg, F., \& Auld, D. P. (2010), motivation is still an important factor in learning despite the developing of innovative ways to deliver instruction, however, there is a lack of research on students' levels of learning motivation and how students can be motivated in blended learning environments. The present study sought to fill in this gap by investigating the relationship between AFL and university students' English learning motivation in blended learning environment.

\section{Research Questions}

This study aims at investigating the relationship between AFL and English learning motivation at university level as well as students' perceptions of this kind of assessment in a blended learning course.

In accordance with the research objectives, this research tries to explore the following research questions:

1) Is there any significant association between Assessment for Learning and students' academic motivation in a blended learning course?

2) Which factor of AFL (monitoring or scaffolding) has a greater influence on students' motivation in a blended learning course?

3) What are students' opinions of AFL in a blended learning course?

\section{Literature Review}

Researchers have made contributions to determine the impact of AFL on students' academic achievement. Most of the findings showed that AFL would exert positive influence on students' performance through effective feedback and regulatory instructions (Hattie, J., \& Timperley, H., 2007; Shute, V. J., 2008). In addition, previous studies also reveal that various types of feedback may have different impacts on academic achievement. If feedback with detailed description can be provided, students will achieve desirable learning results (Hattie, J., \& Timperley, H., 2007; Nyquist, J. B.,2003). Furthermore, AFL enable students to exert more efforts with enhanced self-efficacy and learner autonomy through continuous feedback on students' current learning situation and improvement on next stage by means of supportive classroom evaluation activities. Stiggins, R. (2005) concluded that the incentive mechanism of AFL is to provide learners with clear evidence of their learning progress as well as supportive and individualized advice and practice for their further development, which enable learners to recognize their abilities and perceive their progress. Hattie, J., \& Timperley, H. (2007) pointed out that AFL has a positive impact on motivation by enhancing students' self-efficacy. Up to date, a number of studies have proved their conclusion. Hattie, J. (2008) figured out that instructors' behaviors of scaffolding helps students possess higher level of motivation by conducting a meta-analysis of more than 800 empirical research. Vansteenkiste, M., Lens, W., \& Deci, E. L. (2006) found that learners will become persistent and be more willing to conduct in-depth processing if they are aware of their improvement and ways to enhance their learning performance. The survey conducted by Pat-El et al. (2012) revealed that the two components of AFL (monitoring and scaffolding) were significantly associated with three intrinsic motivational indicators (ability, relevance, autonomy). The meta-analysis of Heitink, M. C. et al. (2016) indicated that students' positive attitudes and their roles in learning are conducive to learner agency and self-directed learning abilities.

Research on AFL in China mainly focuses on compulsory education field (Ding Bangping, 2008; Li Mang et al., 2016). The number of empirical studies on AFL in foreign language course is rather limited. Tang Xiongying (2006) examined the influence of AFL on learning performance by conducting a teaching experiment on freshmen of non-English majors through 12 weeks of teaching practice. The results showed that there was no 
significant difference between the pre-test and the post-test. However, the AFL has significantly improved students' autonomy, self-efficacy as well as their overall motivation. Hu Chajuan (2009) used questionnaires, semi-structured interviews and teaching experiment to investigate the expectations and attitudes towards the practice of AFL and the influence of AFL on students' learning. 76 English majors from two writing classes and 28 instructors participated in the study. The students in the experimental class received a 15 -week instruction with feedback of AFL while the control class adopted traditional assessment. The results of the study showed that the scores of the students in the experimental class were significantly higher than those in the control class and the errors in the composition were significantly less than control class, indicating that teachers' feedback of AFL can effectively improve students' writing proficiency.

The aforementioned two studies provide some enlightenment for this study, inevitably, there exists some limitations. For instance, these studies adopted self-made questionnaires, the validity and reliability cannot be guaranteed. Moreover, there is no objective criteria to measure students' ability or academic achievement.

\section{Methodology}

5.1 Research subjects

The participants are 115 university students with various majors from a selected university in Hubei Province of China. They are 83 female students and 32 male students. They have experienced blended learning course entitled New Horizontal College English for one semester. The instructors have rich knowledge on the theory and practice of blended learning and AFL.

\subsection{Instrument}

5.2.1 Assessment for Learning Questionnaire for Students

Questionnaires made by Pat-El, R. J., Tillema, H., Segers, M., \& Vedder, P. (2013) is employed to investigate students' perceptions of AFL practice. It has been proven that this questionnaire is valid and reliable to measure AFL from the perspective of students in terms of internal consistency, cross-validation and teacher-student invariance (Pat-El, R. J. et al., 2013). The questionnaire contains 28 items, which consists of 16 items of monitoring and 12 items of scaffolding. Five-point Likert scale is used (from totally disagree to totally agree).

The original questionnaire is designed in English, however, the subjects of this study are Chinese university students whose mother tongue is Chinese with English as their foreign language. In order to reduce the possibility of misunderstanding of the items and make the results more reliable, the researcher translated the original questionnaire into Chinese.

After translating the subscales into Chinese, the author presented the translated version to two professors who specialized in English teaching and asked for their suggestions. The author made some modifications of translation according to the professors' feedback.

5.2.2 The Motivation Subscale of Motivated Strategies for Learning Questionnaire

A number of scholars developed instruments to measure motivation on the basis of different theories. In this study, the researcher has looked up some questionnaires that are widely used by researchers such as Pintrich (1991), Keller (1983), Gardner's (2004). After referring to the underlying theories of those questionnaires and consulting the professor who specialized in psychology, the researcher selected the subscale of motivation from Pintrich's Motivated Strategies for Learning Questionnaire (MSLQ) because it covers a wide range of theories. Studies from the past three decades showed that MSLQ can be adapted to many contexts to measure students motivation. The subscale of motivation, which is comprised of three components, namely, value components (intrinsic goal orientation, extrinsic goal orientation, task value); expectancy components (control beliefs; selfefficacy for learning and performance) and affective component (test anxiety).

To avoid the misunderstanding caused by the expression of the items, the questionnaires were translated by the researcher and revised by two professors who specialize in language teaching.

5.2.3 Interview

Based on the results of quantitative data, the researcher selected 6 students ( 4 female students and 2 male students) to conduct semi-structured interviews. The time for interview is about 20 minutes for each student. Questions concerning their opinions of AFL in the blended learning course are asked. The interviews are conducted in English and recorded by the professional recording device.

\section{Results and Discussion}

6.1 The Association between AFL and Motivation

Research question 1: Is there any significant association between Assessment for Learning and students' academic motivation in a blended learning course?

In order to explore the influence of AFL on motivation as well as its impact on components of motivation, Pearson correlation analysis is conducted to analyze the scores of students' AFL questionnaires and motivational questionnaires. The results are shown in Table 1. 
Table 1 Correlation analysis between AFL and components of motivation

\begin{tabular}{|l|l|c|c|c|c|}
\hline & & Motivation & $\begin{array}{l}\text { Value } \\
\text { components }\end{array}$ & $\begin{array}{l}\text { Expectancy } \\
\text { components }\end{array}$ & $\begin{array}{l}\text { Affective } \\
\text { component }\end{array}$ \\
\hline $\begin{array}{l}\text { Assessment for } \begin{array}{l}\text { learning } \\
\text { lerrelation }\end{array} \\
\text { coefficient }\end{array}$ & .476 & .503 & .367 & .081 \\
\cline { 2 - 6 } & Sig. of & 115 & 115 & .003 & .587 \\
\cline { 2 - 6 } & $\begin{array}{l}\text { Number } \\
\text { participants }\end{array}$ & .000 & .000 & 115 & 115 \\
\hline
\end{tabular}

As is shown in Table 1, students' perceptions of AFL are significantly correlated with their motivation. In addition, the influence of AFL on motivation is mainly reflected in the value components and expectancy components. The affective component is not significantly related to AFL. The correlation coefficient between the value components and AFL is higher than the expectancy components, reaching 0.503 . The statistics indicate that students who perceive more AFL practices are more likely to obtain higher motivations for learning. In other words, AFL positively influences students' motivation. In addition, among the three motivational components, AFL did not have a significant influence on the affective component ( $p>.05)$, that is, test anxiety. It can be concluded that the practice of AFL cannot effectively alleviate students' test anxiety in the context of Chinese foreign language teaching.

In order to further examine the relationship between the two components of motivation and AFL, Pearson correlation analysis is conducted on the subscale scores of the two components and AFL. The results are shown in Table 2.

Table 2 Correlation analysis among AFL, value components and expectancy components

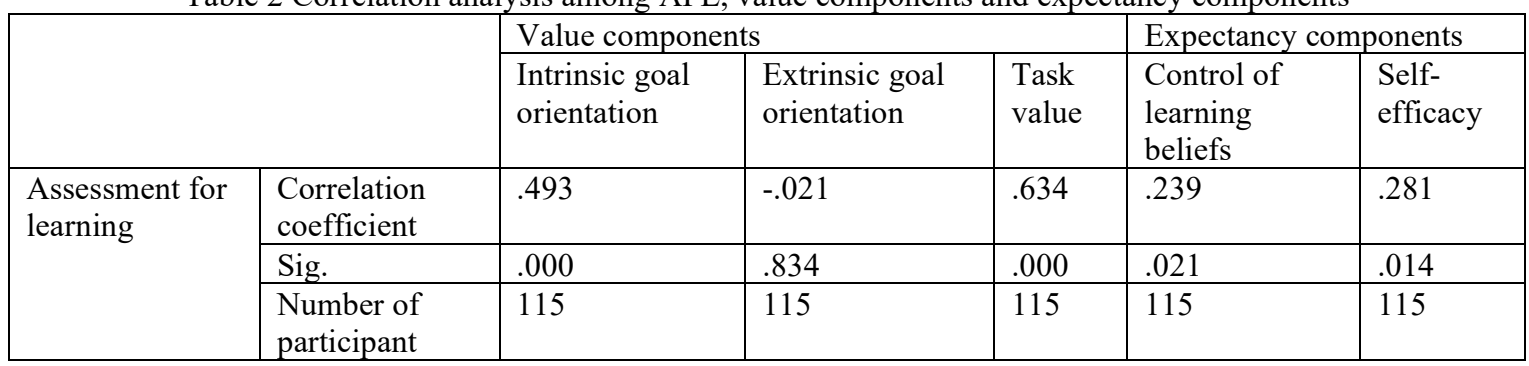

As is shown Table 2, except for extrinsic goal orientation ( $\mathrm{p}>.05)$, other motivational components are significantly correlated with the students' perception of AFL. Among them, the correlation between AFL and intrinsic goal orientation, task value and self-efficacy is relatively high. The correlation coefficients reach 0.493 , 0.634 and 0.281 respectively, while the correlation between AFL and control of learning beliefs is relatively low with the correlation coefficient of 0.239. This result is consistent with previous findings (eg, Hattie, J., 2008; Pat-El, R. J. et al. 2012; Tang Xiongying, 2006), that is, the perception of AFL has a positive impact on learners' self-efficacy, self-confidence and intrinsic motivation, thus improving students' overall motivation.

\subsection{The Influence of Monitoring and Scaffolding on Motivation}

Research question 2: Which factor of AFL (monitoring or scaffolding) has a greater influence on students' motivation in a blended learning course?

To answer research question 2, Pearson analysis was conducted to investigate the correlation between students' scores of monitoring and scaffolding and their overall motivation as well as the correlation between students' scores of monitoring and scaffolding and components of motivation. The results are shown in Table 3. Table 3 Correlation analysis among monitoring, scaffolding and components of motivation

\begin{tabular}{|l|l|l|l|l|l|l|}
\hline & & Motivation & $\begin{array}{l}\text { Intrinsic goal } \\
\text { orientation }\end{array}$ & $\begin{array}{l}\text { Task } \\
\text { value }\end{array}$ & $\begin{array}{l}\text { Control of learning } \\
\text { beliefs }\end{array}$ & $\begin{array}{l}\text { Self } \\
- \\
\text { efficacy }\end{array}$ \\
\hline Monitoring & $\begin{array}{l}\text { Correlation } \\
\text { coefficient }\end{array}$ & .439 & .541 & .604 & .257 & .291 \\
\cline { 2 - 7 } & Sig. & .000 & .000 & .000 & .022 & .009 \\
\cline { 2 - 7 } & $\begin{array}{l}\text { Number of } \\
\text { participants }\end{array}$ & 115 & 115 & 115 & 115 & 115 \\
\hline Scaffolding & $\begin{array}{l}\text { Correlation } \\
\text { coefficient }\end{array}$ & .446 & .375 & .586 & .279 & .232 \\
\cline { 2 - 7 } & Sig. & .000 & .000 & .000 & .031 & 115 \\
\cline { 2 - 8 } \\
$\begin{array}{l}\text { Number of } \\
\text { participants }\end{array}$ & 115 & 115 & 115 & 115 & .020 \\
\hline
\end{tabular}


As is shown in Table 3, the correlation analysis shows that students' scores of monitoring and scaffolding are significantly correlated with their overall motivation scores, with correlation coefficients of 0.439 and 0.446 , respectively, which suggests that monitoring and scaffolding factors have a positive impact on the students' overall motivation. This result is consistent with previous research findings (Shute, V. J., 2008), that is, students who perceive more monitoring and scaffolding feedback are more likely to have higher motivation to learn.

In addition, monitoring and scaffolding are also significantly associated with components of motivation that are influenced by AFL. Compared with scaffolding, monitoring has a greater impact on students' overall motivational. Among the four motivational components, the correlation coefficients between monitoring and three of motivational components are higher than that of scaffolding. This result is inconsistent with the findings of Pat-El, R. et al. (2012), who found that scaffolding has a greater impact on the intrinsic motivation than monitoring.

\subsection{Students' Opinions of AFL in a Blended Learning Course}

Research question 3: What are students' opinions of AFL in a blended learning course?

In order to know students' opinions of AFL, the interviewees are asked to respond to some probing questions. The details are as follows.

1) Intrinsic goal orientation

Intrinsic goal orientation concerns the degree to which the student perceives himself/herself to be participating in a task for reasons such as challenge, curiosity and mastery (Pintrich, P. R., 1991). Consistent with previous research findings (Hattie, J., 2008; Pat-El, R. J. et al. 2012), results of the quantitative data also suggest that students who perceive more AFL tend to have a greater intrinsic motivational orientation.

Interviewees are asked to respond to the question: "Does teachers' practice of AFL (e.g. the clear interpretation of goals, standards and subject content ) increase your interest of learning English?" Below are the students' opinions.

"When teachers clarify the goals of different stages of the learning process and define the criteria for academic success, I feel that I will be able to make progress and participate more actively in activities, thus mastering useful knowledge." (Interviewee 3)

"When teachers clearly interpret the learning objectives and content, I am more willing to learn the course." (Interviewee 4)

Hawe, E., \& Parr, J. (2014) believes that students need to understand learning goals, which is crucial to make progress. In the present study, the interpretation of goals, standards and subject content of AFL practice is believed to stimulate students' intrinsic goal orientation and make them become more willing to obtain knowledge and master skills.

2) Task value

Task value refers to the students' evaluation of the how interesting, how important, and how useful the task is (Pintrich, P. R., 1991). Since task value reflects a kind of motivation cultivated in specific classroom activities and curriculum teaching, so the significant correlation between the perception of AFL and task value proves that AFL is context-dependent and is relevant to the course (Nyquist, J. B., 2003).

Interviewees are asked to respond to the question "What do you think of the tasks that teachers assigned in the class?" One of the interviewee reports that "Teacher often assign tasks that can improve my all-round language skills and provide authentic and interesting materials, which made me feel that the course is very important and practical." (Interview 1)

As Dierick, S., \& Dochy, F. (2001) puts it, one of the characteristics of AFL is that the tasks are challenging, interesting and meaningful. If the task possesses these characteristics, it can have a positive impact on the students' task value, thus enhancing their motivation.

3) Control of learning beliefs

Control of learning refers to students' beliefs that their efforts to learn will result in positive outcomes (Pintrich, P. R., 1991). In other words, learning progress depends on the effort exerted by students themselves, not external factors such as teachers or learning materials. That is to say, if AFL can make students feel that they are able to control the learning process, they will be motivated to achieve the learning goals. The results of the quantitative data indicate that students' perception of AFL is significantly related to their control of learning beliefs due to the influence of scaffolding factors of AFL. Below are the students' opinions.

"Teachers' feedback and suggestions enable me to improve my weaknesses." (Interviewee 2)

"With the help and guidance of teacher, I am confident that I can make progress and achieve desirable learning results." (Interviewee 5)

4) Self-efficacy

Self-efficacy is a self-appraisal of one's ability to master a task (Pintrich, P. R., 1991). The reason why AFL can improve students' self-efficacy is that the monitoring factors constantly provide them with information about their current situation of learning, thus helping them to judge their present learning outcomes and realize the 
gaps between their current state and learning objectives. Meanwhile, scaffolding factor provides timely help and guidance for learners to meet their demands for progress and strengthen their self-confidence in completing the upcoming tasks. The interview data support the quantitative findings.

"A task in the class is often divided into several parts, and we are only required to complete the specified part at different stages. I feel that it is possible for me to complete the sub-goals.” (Interviewee 4)

"Realizing my current ability makes me feel confident in completing tasks. Teachers always give me timely feedback, which enhance my confidence." (Interviewee 6)

The practice of dividing the ultimate goal into several challenging but achievable sub-goals can enhance students' self-efficacy. Students do not feel that they are trying to complete an impossible task. Instead, they are motivated to achieve those sub-goals first.

5) Test anxiety

Test anxiety seems to be a context-specific phenomenon under the Chinese educational environment. One of the interviewee reports that "Slight anxiety encourages me to exert more efforts and urge me to make good preparations in order to behave better in the exam." (Interviewee 4)

However, when students are taking tests, the perception of AFL fail to alleviate their psychological stress. The reason is rooted in the traditional Chinese evaluation culture, which pays too much attention to the final marks ot rankings of the test. Students have suffered from great psychological pressure for a long time since they have experienced such test anxiety in the middle school or even earlier, so it is difficult to change this chronic test anxiety. Below are students' opinions.

"I feel great pressure when taking an exam." (Interviewee 1)

"I am afraid of taking exams. The fear for exam began in my early school years." (Interviewee 3)

6) Extrinsic goal orientation

Extrinsic goal orientation concerns the degree to which the student perceives himself/herself to be participating in a task for reasons such as grades, rewards, performance, evaluation by others, and competition (Pintrich, P. R., 1991). Since these external factors are not directly related to learning itself, AFL cannot have a significant influence on the extrinsic goal orientation because AFL focuses on improving students' learning.

\section{Conclusion}

Results of this research show that AFL in blended learning course has a positive impact on students' motivation by strengthening their intrinsic motivation, task value, control of learning beliefs and self-efficacy. However, AFL cannot affect students' extrinsic motivation or reduce the test anxiety. Both monitoring and scaffolding factors of AFL contribute to this positive influence with monitoring playing a greater role in motivation. Based on the above findings, it is clear that it is worthwhile to advocate and promote the implementation of AFL in the foreign language teaching in China, especially in blended learning courses. Due to the limited number of participants in this study, future research can consider increasing the sample size and explore the impact of AFL on Chinese English learners in a more comprehensive and in-depth manner.

\section{References}

Akgündüz, D., \& Akınoğlu, O. (2017). The Impact of Blended Learning and Social Media-Supported Learning on the Academic Success and Motivation of the Students in Science Education. Education \& Science/Egitim ve Bilim, 42(191).

Clayton, K., Blumberg, F., \& Auld, D. P. (2010). The relationship between motivation, learning strategies and choice of environment whether traditional or including an online component. British Journal of Educational Technology, 41(3), 349-364.

Cowie, B., \& Bell, B. (1999). A model of formative assessment in science education. Assessment in Education: Principles, Policy \& Practice, 6(1), 101-116.

Dang, Y., Zhang, Y., Ravindran, S., \& Osmonbekov, T. (2016). Examining student satisfaction and gender differences in technology-supported, blended learning. Journal of Information Systems Education, 27(2), 119-130.

Dierick, S., \& Dochy, F. (2001). New lines in edumetrics: New forms of assessment lead to new assessment criteria. Studies in educational evaluation, 27(4), 307-329.

Ding Bangping. (2008). From "Formative Assessment" to "Assessment of Learning": the Development of Practice and theory of Classroom Evaluation. Curriculum. Textbook. Pedagogy, (9), 20-25

Hattie, J. (2008). Visible learning: A synthesis of over 800 meta-analyses relating to achievement. routledge.

Hattie, J., \& Timperley, H. (2007). The power of feedback. Review of educational research, 77(1), 81-112.

Hawe, E., \& Parr, J. (2014). Assessment for learning in the writing classroom: An incomplete realisation. Curriculum journal, 25(2), 210-237.

Heitink, M. C., Van der Kleij, F. M., Veldkamp, B. P., Schildkamp, K., \& Kippers, W. B. (2016). A systematic review of prerequisites for implementing assessment for learning in classroom practice. Educational 
research review, 17, 50-62.

Hu Chajuan. (2009). An Empirical Study on the Teachers' feedback of Assessment for Learning in English Majors' Writing. Journal of Yunnan Agriculture University: Social Science Edition, 3(6), 100-105

Jin Yan. (2010). Various Measures of Assessment in Experiential College English. Foreign Languages in China, (1), 68-76

Li Mang, Cai Yujun \& Chen Ping. (2016) On the Enlightenment of British ARG Learning Assessment. Foreign Educational Research, 43(10), 90-100

Nyquist, J. B. (2003). The benefits of reconstruing feedback as a larger system of formative assessment: A metaanalysis(Doctoral dissertation, Vanderbilt University).

Pat-El, R., Tillema, H., \& van Koppen, S. W. (2012). Effects of formative feedback on intrinsic motivation: Examining ethnic differences. Learning and Individual Differences, 22(4), 449-454.

Pat-El, R. J., Tillema, H., Segers, M., \& Vedder, P. (2013). Validation of assessment for learning questionnaires for teachers and students. British Journal of Educational Psychology, 83(1), 98-113.

Pintrich, P. R. (1991). A manual for the use of the Motivated Strategies for Learning Questionnaire (MSLQ).

Sadler, D. R. (2010). Beyond feedback: Developing student capability in complex appraisal. Assessment \& Evaluation in Higher Education, 35(5), 535-550.

Shute, V. J. (2008). Focus on formative feedback. Review of educational research, 78(1), 153-189.

Stiggins, R. (2005). From formative assessment to assessment for learning: A path to success in standards-based schools. Phi Delta Kappan, 87(4), 324-328.

Tang Xiongying. (2006). Research on Assessment in Chinese Language Education (Doctoral dissertation, Shanghai International Studies University)

Vansteenkiste, M., Lens, W., \& Deci, E. L. (2006). Intrinsic versus extrinsic goal contents in self-determination theory: Another look at the quality of academic motivation. Educational psychologist, 41(1), 19-31.

Wang Tongshun, Zhu Xiaotong \& Xu Yingying. (2018). A Study on Effects of Assessment for Learning on Motivation and Writing of Chinese College English Learners. Foreign Language Research, (3), 46-53

Wiggins, G. P. (1993). Assessing student performance: Exploring the purpose and limits of testing. Jossey-Bass. 